\title{
Does brain tumor epidemiology differ from place to another? Saudi single tertiary care center experience.
}

\author{
Ibrahim Alnaami ${ }^{*}$, Leen Sarhan², Ahlam Alqahtani ${ }^{2}$, Amal Alghamdi², Shahad Alkhashrami², \\ Ossama Mostafa ${ }^{3}$ \\ ${ }^{1}$ Department of Surgery, Neurosurgery Section, King Khalid University, Abha, Saudi Arabia \\ ${ }^{2}$ Department of Surgery, King Khalid University, Abha, Saudi Arabia \\ ${ }^{3}$ Community and Family Medicine Department, King Khalid University, Abha, Saudi Arabia
}

\begin{abstract}
Background: Brain tumors are associated with marked disability and mortality. Understanding the patterns and epidemiological characteristics associated with brain tumors can be crucial to their treatment.

Objective: To explore the magnitude and epidemiological features of primary brain tumors among patients admitted to Aseer Central Hospital (ACH), Abha City, Saudi Arabia, and to identify different decisions for their management.

Methodology: All hospital records of brain tumor patients admitted to ACH from 2015-2017 were reviewed. Collected data included patients' demographic characteristics, clinical findings, histopathological diagnosis, and management.

Results: During the aforementioned period, a total of 100 patients with primary brain tumors were admitted to $\mathrm{ACH}$. The most commonly presenting symptoms were headache (72\%), vomiting, dizziness, and focal motor deficits (25\% for all). Tumor location was mostly at the frontal or parietal lobes. Among those who underwent surgery, meningioma grade I was the most frequently diagnosed $(41.7 \%)$. The mean surgical time was $4.2 \pm 1.6 \mathrm{~h}$. Most patients who underwent surgery at ACH stayed in the intensive care unit anywhere from $1 \mathrm{~d}$ or $\mathbf{2 - 4} \mathrm{d}$ (34\% and $40 \%$, respectively). The Glasgow outcome scale scores of most patients $(91.7 \%)$ indicated that the patients had a good recovery. However, one patient died $(1.7 \%)$, one was in a persistent vegetative state $(1.7 \%)$, and three sustained moderate disability $(5 \%)$.

Conclusion: Most patients with brain tumors admitted to ACH undergo surgery. Meningioma grade I is the most commonly encountered brain tumor, and this finding may reflect different epidemiological findings from the internationally accepted concept that glioblastoma multiforme is the most common brain tumor. The most common locations for brain tumors are the frontal and parietal lobes.
\end{abstract}

Keywords: Brain neoplasms, Epidemiology, Clinical picture, Histopathology, Saudi Arabia.

Accepted on July 16, 2018

\section{Introduction}

Brain tumors comprise a large group of benign and malignant neoplasms [1]. Primary malignant brain tumors are relatively rare; however, over the last few decades, it has been observed that the incidence rates for brain tumors have been increasing. This increase may be due to improved diagnostic techniques and to changes in tumor coding and classification $[2,3]$.

Brain tumors constitute a mixed group of neoplasms that originate from intracranial tissues and the meninges, with degrees of malignancy that can range from benign to aggressive. Benign brain tumors can be lethal due to their site in the brain, their ability to infiltrate locally, and their tendency to transform to malignancy [4]. Malignant brain tumors account for $1.4 \%$ of all cancers and $2.3 \%$ of all cancer-related deaths. They are particularly deleterious since they can interfere with the normal brain functions that are essential for life [5]. These tumors are usually associated with marked disability and mortality. Accordingly, the ability to understand the patterns and epidemiological characteristics associated with brain tumors can be crucial to the prevention of these lesions [6].

Brain tumors represent among the most common human diseases. It has been estimated that the prevalence of brain tumors among the Saudi population is $0.3 \%$ [7]. In the Middle East, Iran ranks highest with respect to the highest prevalence rate of brain tumors, with the Kingdom of Saudi Arabia (KSA) ranking second [8]. However, most local cancer registries in the Middle East do not meet international standards [6], and 
there are a few studies that have analyzed the epidemiology of brain tumors in the region [7-11]. Accordingly, there is a lack of information related to the epidemiological characteristics of these tumors in Arabic and Middle Eastern countries, including KSA.

This study aims to explore the magnitude and epidemiological features of primary brain tumors among patients admitted to Aseer Central Hospital (ACH), Abha City, Saudi Arabia, and to identify the different decisions for their management.

\section{Materials and Methods}

This research followed a retrospective study design. All hospital records of patients with brain tumors who had been admitted to ACH from January 2015 to December 2017 were reviewed. ACH is a tertiary care hospital located in Abha City, Aseer Region at the South-Western part of Saudi Arabia.

According to the $\mathrm{ACH}$ protocol and guidelines for the management of brain tumor cases, operable cases undergo surgery and postoperative follow up at the hospital. Some cases may be referred to oncology-specialized centers in Jeddah or Riyadh after surgery to continue chemotherapy or radiotherapy sessions. Upon their request, patients are free to leave the hospital against medical advice (LAMA). So, our patients ended up being in 3 groups, first group, includes all operated brain tumors patients at $\mathrm{ACH}$, second group, involves patients who were referred to higher centers that has specialized oncology centers for chemo and radiotherapy, and third group, involves patients who left the hospital against medical advice without formulating any plans for treatment. Collected data included patients' demographic characteristics, clinical findings, histopathological diagnosis, and management decisions.

Data entry and analysis were completed using the Statistical Package for the Social Sciences (SPSS version 23.0). Data were analyzed using descriptive statistics in the arrangement of frequencies and percentages for qualitative variables, and range, means, and standard deviations for quantitative variables. Inferential statistics were applied using the chisquare test $\left(\chi^{2}\right)$ and Kruskal-Wallis $\mathrm{H}$ test. $\mathrm{P}$-values $<0.05$ were considered statistically significant.

\section{Results}

Between January 2015 and December 2017, a total of 100 patients with brain tumors were admitted to $\mathrm{ACH}$ with a diagnosis of primary brain tumor. The decisions for management of these cases included operation (60 patients), being referred to specialized hospitals in Jeddah or Riyadh (14 patients), or LAMA (26 patients) (Figure 1).

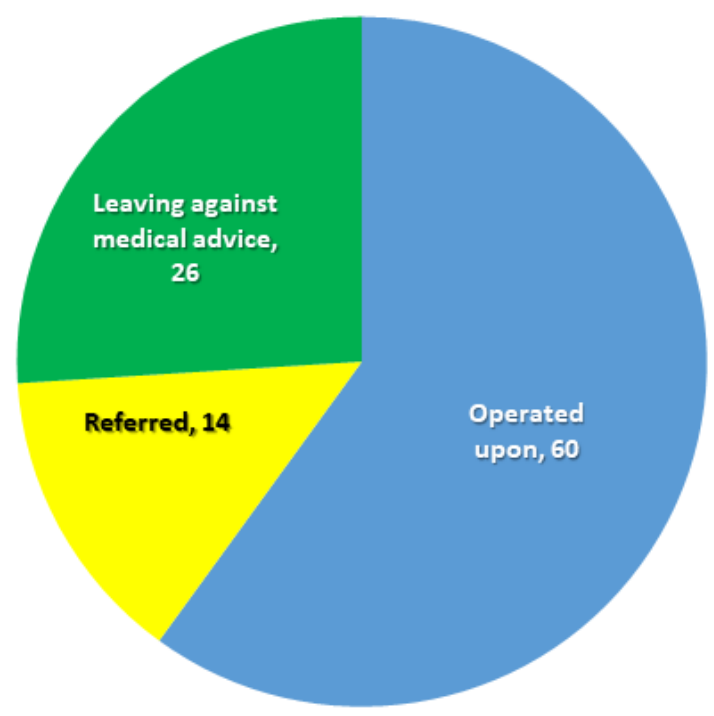

Figure 1. Different decisions for management of primary brain tumor patients admitted to Aseer Central Hospital during 2015-2017.

Table 1 shows that the age of most patients who were operated upon $(40 \%)$ and those who were referred $(50 \%)$ was $60 \mathrm{y}$ or more, while $34.6 \%$ of those who opted for LAMA were 40-59 $\mathrm{y}$ of age. There were no statistically significant differences in patients' outcomes according to their age groups. Most of our patients were females $(56.7 \%$ were operated upon, $57.1 \%$ were referred, and $65.4 \%$ opted for LAMA). There were no statistically significant differences in patients' outcomes according to their gender. Most of our patients were of Saudi origin $(73.3 \%$ were operated upon, $92.9 \%$ were referred, and $92.3 \%$ opted for LAMA). There were no statistically significant differences in patients' outcomes according to their nationality.

Table 1. Socio-demographic characteristics of the study groups with brain tumor according to their management decisions.

\begin{tabular}{|c|c|c|c|c|c|c|c|c|}
\hline \multirow{3}{*}{ Sample char } & & \multicolumn{6}{|c|}{ Management decisions } & \multirow[t]{3}{*}{${ }^{M C} C_{P}$} \\
\hline & & \multicolumn{2}{|c|}{ Operated $(n=60)$} & \multicolumn{2}{|c|}{ Referred $(n=14)$} & \multicolumn{2}{|c|}{ LAMA ( $n=26)$} & \\
\hline & & No. & $\%$ & No. & $\%$ & No. & $\%$ & \\
\hline \multirow{4}{*}{ Age in years } & $<20 y$ & 11 & 18.3 & 2 & 14.3 & 4 & 15.4 & \multirow{4}{*}{0.431} \\
\hline & $20-39$ & 11 & 18.3 & 2 & 14.3 & 8 & 30.8 & \\
\hline & $40-59$ & 14 & 23.3 & 3 & 21.4 & 9 & 34.6 & \\
\hline & $60+$ & 24 & 40 & 7 & 50 & 5 & 19.2 & \\
\hline Gender & Male & 26 & 43.3 & 6 & 42.9 & 9 & 34.6 & 0.743 \\
\hline
\end{tabular}




\begin{tabular}{lllllllll} 
& Female & 34 & 56.7 & 8 & 57.1 & 17 & 65.4 \\
\hline \multirow{2}{*}{ Nationality } & Saudi & 44 & 73.3 & 13 & 92.9 & 24 & 92.3 \\
\cline { 2 - 7 } & Non Saudi & 16 & 26.7 & 1 & 7.1 & 2 & 7.7 & * 0.055 \\
\hline
\end{tabular}

LAMA: Left Against Medical Advice; ${ }^{M C} \mathrm{P}$ : Mont Carlo exact Probability; ${ }^{*} \mathrm{P} \leq 0.05$ (significant).

Table 2 shows that the most commonly presenting symptoms for patients with brain tumors were headache (72\%), vomiting, dizziness, and focal motor deficits (25\% for all). Patients' outcomes differed significantly according to their presenting symptoms ( $\mathrm{P}=0.03)$, with headache being highest among patients with LAMA (76.9\%), while vomiting and dizziness were highest among referred cases $(28.6 \%$ and $42.9 \%$, respectively).

Table 2. Clinical presentation of patients with brain tumor according to their management decisions.

\begin{tabular}{|c|c|c|c|c|c|c|c|}
\hline \multirow{3}{*}{ Clinical presentation } & \multicolumn{6}{|c|}{ Management decisions } & \multirow[t]{3}{*}{${ }^{\mathrm{MC}} \mathbf{P}$} \\
\hline & \multicolumn{2}{|c|}{$\begin{array}{l}\text { Operated } \\
(n=60)\end{array}$} & \multicolumn{2}{|c|}{$\begin{array}{l}\text { Referred } \\
(n=14)\end{array}$} & \multicolumn{2}{|c|}{ LAMA ( $n=26)$} & \\
\hline & No. & $\%$ & No. & $\%$ & No. & $\%$ & \\
\hline Headache & 43 & 71.7 & 9 & 64.3 & 20 & 76.9 & \\
\hline Vomiting & 14 & 23.3 & 4 & 28.6 & 7 & 26.9 & \\
\hline Dizziness & 15 & 25 & 6 & 42.9 & 4 & 15.4 & \\
\hline Focal motor deficit & 14 & 23.3 & 5 & 35.7 & 6 & 23.1 & \\
\hline Seizures & 9 & 15 & 2 & 14.3 & 6 & 23.1 & \\
\hline Affected LOC & 8 & 13.3 & 4 & 28.6 & 3 & 11.5 & \\
\hline Altered mental status & 9 & 15 & 2 & 14.3 & 4 & 15.4 & $0.030^{*}$ \\
\hline Visual disturbances & 9 & 15 & 1 & 7.1 & 4 & 15.4 & \\
\hline
\end{tabular}

\begin{tabular}{lllllll}
\hline Gait disturbance & 4 & 6.7 & 5 & 35.7 & 2 & 7.7 \\
\hline Nausea & 5 & 8.3 & 0 & 0 & 2 & 7.7 \\
\hline Numbness & 4 & 6.7 & 2 & 14.3 & 0 & 0 \\
\hline Speech deficits & 2 & 3.3 & 3 & 21.4 & 0 & 0 \\
\hline FSA & 0 & 0 & 2 & 14.3 & 0 & 0 \\
\hline Others & 9 & 15 & 2 & 14.3 & 1 & 3.8 \\
\hline
\end{tabular}

$\mathrm{P}=0.030$; ${ }^{\mathrm{MC}} \mathrm{P}$ : Mont Carlo exact probability; ${ }^{*} \mathrm{P} \leq 0.05$ (significant); LAMA: Left Against Medical Advice; LOC: Level of Consciousness; FSA: Focal Sensory Abnormalities.

Table 3 shows that most patients underwent diagnostic imaging either on the same day of admission or the next day. The location of the tumor was mostly at the frontal or parietal lobes. Most patients had one tumor. Almost half of tumors were on the right side. The tumor size varied greatly, with a median of $8 \mathrm{~mm}^{3}$ among those who were operated upon, 12.1 $\mathrm{mm}^{3}$ among those who were referred, and $11.7 \mathrm{~mm}^{3}$ among those who opted for LAMA. There were no statistically significant differences in patient outcomes based on their period of admission until the time they underwent diagnostic imaging. Further, there were no significant differences in patient outcomes based on tumor location, number of tumors, side, or size.

Table 3. Tumor characteristics according to patients' management decisions.

\begin{tabular}{|c|c|c|c|c|c|c|c|c|}
\hline \multirow{3}{*}{ Tumor data } & & \multicolumn{6}{|c|}{ Management decisions } & \multirow[t]{3}{*}{ MCP } \\
\hline & & \multicolumn{2}{|c|}{ Operated $(n=60)$} & \multicolumn{2}{|c|}{ Referred $(n=14)$} & \multicolumn{2}{|c|}{ LAMA $(n=26)$} & \\
\hline & & No. & $\%$ & No. & $\%$ & No. & $\%$ & \\
\hline \multirow{4}{*}{$\begin{array}{l}\text { Days from admission } \\
\text { to imaging }\end{array}$} & Same day & 17 & 28.3 & 3 & 21.4 & 12 & 46.2 & \multirow{4}{*}{0.412} \\
\hline & $1 \mathrm{~d}$ & 19 & 31.7 & 4 & 28.6 & 9 & 34.6 & \\
\hline & $1-3$ & 15 & 25 & 4 & 28.6 & 2 & 7.7 & \\
\hline & $4+$ & 9 & 15 & 3 & 21.4 & 3 & 11.5 & \\
\hline \multirow{5}{*}{ Location } & Frontal lobe & 18 & 30 & 4 & 28.6 & 11 & 42.3 & \multirow{5}{*}{0.225} \\
\hline & Temporal lobe & 10 & 16.7 & 5 & 35.7 & 2 & 7.7 & \\
\hline & Parietal lobe & 17 & 28.3 & 3 & 21.4 & 12 & 46.2 & \\
\hline & Occipital lobe & 10 & 16.7 & 4 & 28.6 & 3 & 11.5 & \\
\hline & Cerebellum & 11 & 18.3 & 1 & 7.1 & 4 & 15.4 & \\
\hline
\end{tabular}




\begin{tabular}{|c|c|c|c|c|c|c|c|c|}
\hline & Brain stem & 2 & 3.3 & 2 & 14.3 & 1 & 3.8 & \\
\hline & Ventricles & 4 & 6.7 & 1 & 7.1 & 1 & 3.8 & \\
\hline & Basal ganglia & 1 & 1.7 & 1 & 7.1 & 0 & 0 & \\
\hline & Supra cellular & 2 & 3.3 & 0 & 0 & 0 & 0 & \\
\hline & Pituitary gland & 2 & 3.3 & 0 & 0 & 0 & 0 & \\
\hline & Posterior fossa & 1 & 1.7 & 0 & 0 & 0 & 0 & \\
\hline & Thalamus gland & 0 & 0 & 0 & 0 & 0 & 0 & \\
\hline & Genu of corpus callosum & 0 & 0 & 1 & 7.1 & 0 & 0 & \\
\hline & Orbital apex & 0 & 0 & 0 & 0 & 1 & 3.8 & \\
\hline \multirow{3}{*}{ Number } & Single & 43 & 71.7 & 7 & 50 & 17 & 65.4 & \multirow{3}{*}{0.224} \\
\hline & Two & 16 & 26.7 & 5 & 35.7 & 8 & 30.8 & \\
\hline & Multiple & 1 & 1.7 & 2 & 14.3 & 1 & 3.8 & \\
\hline \multirow{2}{*}{ Side } & Right & 31 & 51.7 & 8 & 57.1 & 10 & 41.7 & \multirow{2}{*}{0.601} \\
\hline & Left & 29 & 48.3 & 6 & 42.9 & 14 & 58.3 & \\
\hline \multirow{3}{*}{ Size $\left(\mathrm{mm}^{3}\right)$} & Range & $0.38-153.2$ & & $0.38-172.4$ & & $0.80-120$ & & \multirow{3}{*}{$0.398^{\#}$} \\
\hline & Mean \pm SD & $22.2 \pm 30.9$ & & $38.6 \pm 10.6$ & & $27.5 \pm 34.6$ & & \\
\hline & Median & 8 & & 12.1 & & 11.7 & & \\
\hline
\end{tabular}

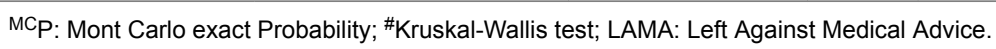

Table 4 shows that among those who were operated upon, the most commonly diagnosed pathological types of brain tumors were meningioma grade I (41.7\%), followed by high-grade glioma/glioblastoma (16.7\%); Most surgeries were performed by one or two surgeons ( $18.3 \%$ and $58.3 \%$, respectively). Most surgeries $(75 \%)$ necessitated blood transfusion. Hospital stays from admission until surgery varied greatly (1-33 d), with a mean of $7.8 \pm 6.3 \mathrm{~d}$ and a median of $6 \mathrm{~d}$. Duration of surgery also varied greatly $(1-8 \mathrm{~h})$, with a mean of $4.2 \pm 1.6 \mathrm{~h}$ and a median of $4 \mathrm{~h}$.

Table 4. Surgery data as recorded among brain tumor patients who underwent surgery at $\mathrm{ACH}(n=60)$.

\begin{tabular}{|c|c|c|c|}
\hline \multirow{2}{*}{ Surgery dat } & & \multicolumn{2}{|c|}{ Operated upon } \\
\hline & & No. & $\%$ \\
\hline \multirow{9}{*}{$\begin{array}{l}\text { Pathology } \\
\text { type }\end{array}$} & Meningioma grade I & 25 & 41.7 \\
\hline & Astrocytoma & 5 & 8.3 \\
\hline & High grade glioma/GBM & 10 & 16.7 \\
\hline & Neuroendocrine carcinoma & 1 & 1.7 \\
\hline & Hemangioblastoma & 2 & 3.3 \\
\hline & Medulloblastoma & 1 & 1.7 \\
\hline & Glial tumor & 1 & 1.7 \\
\hline & Schwannoma & 1 & 1.7 \\
\hline & Central neurocytoma & 1 & 1.7 \\
\hline
\end{tabular}

\begin{tabular}{|c|c|c|c|}
\hline & Ependymoma WHO grade II-III/IV & 2 & 3.3 \\
\hline & Craniopharyngioma & 2 & 3.3 \\
\hline & Oligoastrocytoma & 1 & 1.7 \\
\hline & Pituitary adenoma & 2 & 3.3 \\
\hline & Metastatic urothelial cell carcinoma & 1 & 1.7 \\
\hline & Atypical meningioma I-II & 5 & 8.3 \\
\hline \multirow{4}{*}{$\begin{array}{l}\text { Number } \\
\text { surgeons }\end{array}$} & 1 & 11 & 18.3 \\
\hline & 2 & 35 & 58.3 \\
\hline & 3 & 9 & 15 \\
\hline & 4 & 5 & 8.3 \\
\hline \multirow{2}{*}{$\begin{array}{l}\text { Blood } \\
\text { transfusion }\end{array}$} & No & 15 & 25 \\
\hline & Yes & 45 & 75 \\
\hline \multirow{3}{*}{$\begin{array}{l}\text { Days from } \\
\text { admission till } \\
\text { surgery }\end{array}$} & Range & $1-33$ & \\
\hline & Mean \pm SD & $7.8 \pm 6.3$ & \\
\hline & Median & 6 & \\
\hline \multirow{3}{*}{$\begin{array}{l}\text { Duration of } \\
\text { surgery }(h)\end{array}$} & Range & $1-8$ & \\
\hline & Mean \pm SD & $4.2 \pm 1.6$ & \\
\hline & Median & 4 & \\
\hline
\end{tabular}

Table 5 shows that most brain tumor patients who underwent surgery at ACH stayed in the Intensive Care Unit (ICU) for $1 \mathrm{~d}$ or $2-4 \mathrm{~d}$ (34\% and $40 \%$, respectively). Their ward periods of 
stay were mainly $7-13 \mathrm{~d}$ or $14+\mathrm{d}(33.9 \%$ and $54.2 \%$, respectively). According to the Glasgow Coma Scale, most patients $(91.7 \%)$ had a good recovery; however, one patient died $(1.7 \%)$, one was in a persistent vegetative state $(1.7 \%)$, and three sustained moderate disability (5\%).

Table 5. Outcome data as recorded among brain tumor patients who underwent surgery at $\mathrm{ACH}(\mathrm{n}=60)$.

\begin{tabular}{lllll}
\hline \multirow{2}{*}{ Outcome } & & \multicolumn{2}{c}{ Operated } \\
\cline { 2 - 4 } & & No. & $\%$ \\
\hline ICU stay (d) & One day & 17 & 34 \\
\cline { 2 - 5 } & $2-4$ & 20 & 40 \\
\cline { 2 - 5 } & $5+$ & 13 & 26 \\
\hline Ward stay (d) & $1-6$ & 7 & 11.9 \\
\cline { 2 - 5 } & $7-13$ & 20 & 33.9 \\
\cline { 2 - 5 } & $14+$ & 32 & 54.2 \\
\hline Glasgow & Died & 1 & 1.7 \\
\cline { 2 - 5 } & Persistent vegetative/minimal responsiveness & 1 & 1.7 \\
\cline { 2 - 5 } & Moderate disability & 3 & 5 \\
\cline { 2 - 5 } & Good recovery & 55 & 91.7 \\
\cline { 2 - 5 } & & 20 &
\end{tabular}

\section{Discussion}

The results of the current study showed that between January 2015 and December 2017, 100 patients with brain tumors were admitted to $\mathrm{ACH}$. The age of most patients who were operated on and who were referred to specialist hospitals was $60 \mathrm{y}$ or more, while most of those who opted for LAMA were aged 40-59 y. Moreover, most of our patients were females. In addition, almost two thirds of patients were operated upon, while $14 \%$ were referred, and $26 \%$ opted for LAMA.

Our findings are in accordance with those of Tamimi et al. [6], in Jordan, as those researchers reported a higher incidence of brain tumors among females $(5.38$ per 100,000$)$ compared with 4.65 per 100,000 in males. Individuals in the 55-59-y age range had the highest incidence of brain tumors.

Brain tumor patients are usually referred to specialized medical oncology centers in Riyadh (e.g., the King Faisal Specialist Hospital and Research Center). Referrals are usually decided for late-stage patients or when management necessitates advanced diagnostic or therapeutic facilities that are not currently available at $\mathrm{ACH}$.

Conversely, Ibrahim et al. [12] stated that discharges against medical advice, or self-discharges, are examples of when patients' preferences are accounted for when making the decision of when to discharge. In some instances, patients decide not to wait for administrative delays in the discharge process. On other occasions, pressing domestic or social concerns may lead patients to leave the hospital before their physicians believe they are ready.
The outcomes of our brain tumor patients (whether they were operated upon, referred to a specialist hospital, or opted for LAMA) did not differ significantly based on their sociodemographic characteristics.

The findings of the current study showed that the most commonly presenting symptoms among patients with brain tumors were headache (72\%), vomiting, dizziness, and focal motor deficits $(25 \%$ for all). Patients' outcomes differed significantly according to their presenting symptoms $(\mathrm{P}=0.03)$.

These findings are in accordance with those reported by Hamilton et al. [13], who stated that up to $70 \%$ of patients with brain tumors experience headache during the course of their illness. Bangash [8] reported that the most common presenting symptoms among brain tumor patients were headache $(68 \%)$, followed by nausea and vomiting (32\%). However, Grant [14] reported that the most common first symptoms among brain tumor patients were seizures $(47 \%)$, headache $(23 \%)$, and focal symptoms (11\%).

The results of this study revealed that most brain tumor patients underwent diagnostic imaging either on the same day of admission or the next day. The tumors were mostly located at the frontal or parietal lobes. Most patients only had a single tumor. There was no predilection for a certain side, as almost half of tumors were on the right side. These findings are in accordance with those of several studies that reported how the frontal lobe was reported to be the most common site of brain tumors [8,15-18].

The present study revealed that among those who were operated upon, the most commonly diagnosed pathological types of brain tumors were meningioma grade I, and highgrade glioma/glioblastoma. Most surgeries were performed by one or two surgeons. Most surgeries necessitated blood transfusion. Hospital stay from admission until surgery varied greatly (range: 1-33 d). The duration of surgery also varied greatly (range: $1-8 \mathrm{~h}$ ). Most brain tumor patients stayed in the ICU for $1 \mathrm{~d}$ or $2-4 \mathrm{~d}$, and their ward stays were mainly 7-13 $\mathrm{d}$ or $14+\mathrm{d}$ in duration. The Glasgow Coma Scale scores for most patients indicated good recovery, with $1 \%$ postoperative mortality.

Ohgaki [19] stated that gliomas account for more than $70 \%$ of all brain tumors. Of these, glioblastomas are the most frequent and malignant histologic type. Dasenbrock et al. [20] reported that the median hospital stay after surgery for brain tumors was $4 \mathrm{~d}$, with $27.7 \%$ of patients having a hospital stay of at least 8 d. Williams et al. [21] reported that postoperative mortality is almost 3\%.

There are geographical variations in the distribution of brain tumors [22]. Therefore, epidemiological studies are important for exploring the magnitude and demographic distribution of brain tumors [23]. In Iran, meningiomas are reported to be the most common tumors [24,25], whereas the incidence of lowgrade gliomas is highest in Syria [10].

In conclusion, most brain tumor patients admitted to a tertiary care hospital in Abha City, KSA, undergo surgery; however, 
some patients must be referred to specialized oncology centers, while others prefer LAMA. Furthermore, the size of brain tumors varies greatly. Meningioma grade $\mathrm{I}$ is the most commonly encountered brain tumor, followed by high-grade glioma/glioblastoma. The most common locations for brain tumors are the frontal and parietal lobes. The duration of surgery varies greatly, which may last up to $8 \mathrm{~h}$, and most patients require a blood transfusion. One surgeon usually operates on those patients; however, some surgeries require more than one surgeon. Finally, the duration of hospital stay varies greatly, which may last longer than a month.

\section{Acknowledgment}

English-language editing of this manuscript was provided by Journal Prep Services.

\section{References}

1. de Robles P, Fiest KM, Frolkis AD, Pringsheim T, Atta C, St Germaine-Smith C. The worldwide incidence and prevalence of primary brain tumors: a systematic review and meta-analysis. Neuro Oncol 2015; 17: 776-783.

2. Bondy ML, Scheurer ME, Malmer B, Barnholtz-Sloan JS, Davis FG, Il'yasova D. Brain tumor epidemiology: consensus from the Brain Tumor Epidemiology Consortium. Cancer 2008; 113: 1953-1968.

3. Andersson U, Wibom C, Cederquist K, Aradottir S, Borg A, Armstrong GN. Germline rearrangements in families with strong family history of glioma and malignant melanoma, colon, and breast cancer. Neuro Oncol 2014; 16: 1333-1340.

4. McKinney PA. Brain tumours: incidence, survival, and aetiology. J Neurol Neurosurg Psychiatry 2004; 75: 12-17.

5. Society AC. Cancer facts and figures. Am Cancer Society 2000.

6. Tamimi AF, Tamimi I, Abdelaziz M, Saleh Q, Obeidat F, Al-Husseini M. Epidemiology of malignant and nonmalignant primary brain tumors in Jordan. Neuroepidemiology 2015; 45: 100-108.

7. Ibrahim AW. CNS tumors in Eastern Saudi Arabia. Neurosurg Rev 1992; 15: 295-302.

8. Bangash M. Incidence of brain tumours at an academic centre in

9. Western Saudi Arabia. East African Med J 2011; 88: 5.

10. Al-Sheyyab M, Bateiha A, Kayed SE, Hajjawi B. The incidence of childhood cancer in Jordan: a populationbased study. Ann Saudi Med 2003; 23: 260-263.

11. Kadri H, Mawla AA, Murad L. Incidence of childhood brain tumors in Syria (1993-2002). Pediatr Neurosurg 2005; 41: 173-177.

12. El-Gaidi MA. Descriptive epidemiology of pediatric intracranial neoplasms in Egypt. Pediatr Neurosurg 2011; 47: 385-395.

13. Ibrahim SA, Kwoh CK, Krishnan E. Factors associated with patients who leave acute-care hospitals against medical advice. Am J Public Health 2007; 97: 2204-2208.
14. Hamilton W, Kernick D. Clinical features of primary brain tumours: a case-control study using electronic primary care records. Br J Gen Pract 2007; 57: 695-699.

15. Grant R. Overview: Brain tumour diagnosis and management/Royal College of Physicians guidelines. J Neurol Neurosurg Psychiatry 2004; 75: 18-23.

16. Jamal S, Moghal S, Mamoon N, Mushtaq S, Luqman M, Anwar M. The pattern of malignant tumours: tumour registry data analysis, AFIP, Rawalpindi, Pakistan (1992-2001). J Pak Med Assoc 2006; 56: 359-362.

17. Jalali R, Datta D. Prospective analysis of incidence of central nervous tumors presenting in a tertiary cancer hospital from India. J Neurooncol 2008; 87: 111-114.

18. Masoodi T GR, Singh JP, Khajuria A. Pattern of central nervous system neoplasm: A study of 106 cases. JK Pract 2012; 17: 5 .

19. Mondal S PR, Pal S, Biswas B, Banerjee A, Bhattacharyya D. Clinico-pathological pattern of brain tumors: A 3-year study in a tertiary care hospital in India. Clin Cancer Investig J 2016; 5: 4.

20. Ohgaki H. Epidemiology of brain tumors. Methods Mol Biol 2009; 472: 323-342.

21. Dasenbrock HH, Liu KX, Devine CA, Chavakula V, Smith TR, Gormley WB. Length of hospital stay after craniotomy for tumor: a national surgical quality improvement program analysis. Neurosurg Focus 2015; 39: E12.

22. Williams M, Treasure P, Greenberg D, Brodbelt A, Collins P. Surgeon volume and 30 day mortality for brain tumours in England. Br J Cancer 2016; 115: 1379-1382.

23. Alimohamadi SM, Ghodsi SM, Ketabchi SE. Epidemiologic patterns of primary brain tumors in Iran. Asian Pac J Cancer Prev 2008; 9: 361-362.

24. McCarthy BJ, Kruchko C. Central brain tumor registry of the United S. Consensus conference on cancer registration of brain and central nervous system tumors. Neuro Oncol 2005; 7: 196-201.

25. Mehrazin M, Rahmat H, Yavari P. Epidemiology of primary intracranial tumors in Iran, 1978-2003. Asian Pac J Cancer Prev 2006; 7: 283-288.

\section{*Correspondence to}

Ibrahim Alnaami

Surgery Department

Neurosurgery Section

King Khalid University

Abha

Saudi Arabia 